\title{
Mission Effectiveness and European Airspace: U.S. Air Force CNS/ATM Planning for Future Years
}

\author{
Edward Wigfield, Kelly Connolly, Alexander Alshtein, \\ James DeArmon, Richard Flournoy, William Hershey, \\ John James, Paula Mahoney, Jennifer Mathieu, \\ John Maurer, Paul Ostwald \\ The MITRE Corporation \\ 202 Burlington Rd. \\ Bedford, Massachusetts
}

\begin{abstract}
This paper describes a model-driven analysis to assess the mission effectiveness of specific Communication Navigation Surveillance/Air Traffic Management (CNS/ATM) capabilities to support the U.S. Air Force (USAF). Two layers of interactions were investigated: first, within the USAF enterprise, between the Combat Air Forces and the Mobility Air Forces, and second, between the USAF and civilian ATM.

The analysis sought to answer the following question: "What is the degradation in mission effectiveness, assuming delays in planned avionics upgrades, in light of current and continuing denial of military-preferred routings and altitudes in civil European airspace?” Two hypothetical scenarios were considered, each with different forward basing of fighters. In each scenario, CNS enabled and CNS not-enabled aircraft were examined for mission effectiveness. Also presented are the effects of missed strike packages on the Air Operations Center (AOC) and on tanker utilization.
\end{abstract}




\section{Background and Introduction}

On April 3, 1996 an Air Force CT-43 (the military version of the Boeing 737) crashed in bad weather while attempting a landing at Dubrovnik, Croatia—-killing 35 people including U.S. Secretary of Commerce Ronald H. Brown and a trade delegation of a dozen U.S. business executives. About two months later, Cable Network News (CNN) reported that an Air Force investigation had found poor navigation equipment was partly to blame for the incident $[1,2]$.

As a direct result of this event, the Secretary of Defense mandated enhancements to navigation safety for U. S. military aircraft and in May 1997 the Chief of Staff of the Air Force established the Global Access, Navigation, and Safety (GANS) program. General T. S. Moorman, Vice Chief of Staff stated: "The purpose of GANS is to serve as a focal point for Air Force requirements, acquisition, and funding policy recommendations for GANS-related programs." In March 2001, Air Force Policy Directive 63-13 was issued "to ensure that all Air Force acquisitions and modifications conform to the appropriate civil communication, navigation, surveillance/air traffic management (CNS/ATM) performance standards to guarantee access to worldwide controlled airspace." The directive goes on to note the following. "Aircraft not meeting CNS/ATM standards may be relegated to longer delays on the ground waiting for clearance, directed to operate on less optimum routes, or may be restricted from some airspace altogether [3].

The subject of CNS/ATM standards is complex. Standards are not uniform across countries, plus they are not static - they evolve over time. Moreover, some countries grant exemptions or waivers to U.S. Civilian air traffic managers, and government oversight organizations react to the growth of air traffic and new technology by developing new requirements, rules, and processes for using sovereign airspace. One of the key roles of GANS is to bridge the civilian and military communities. Integrated Product Teams (IPTs) have been set up to focus on CNS/ATM requirements, acquisition, and funding policies for the Air Force enterprise. The Standing-IPT and Working-IPT resolve tactical issues, and are co-chaired by U.S. Air Force Colonels representing operations ("XOR") and acquisitions ("AQQ"). The GANS Integrating IPT (I-IPT) is co-chaired by Air Force Major Generals from these organizations.

In November 2003, the Electronic Systems Command (ESC/GA) received direction from the GANS I-IPT to conduct a CNS/ATM impact analysis. The goal of the study was to identify operational, cost, and safety impacts of non-compliance with civil CNS/ATM requirements. During the period of March 2004 to September 2004, a model-based analysis focused on the impacts to mission operations resulting from non-compliance with CNS/ATM mandates. The results of the first phase of the study were approved in November 2004 with the recommendation to mature this new analysis capability to support enterprise decision making. This paper documents the results of the second phase of the impact study, giving special attention to analysis at the system-of-systems or enterprise scale.

To the knowledge of the authors, few previous studies similar to this one are in the open literature. A study by RAND [4] looks at USAF basing "in theatre," and explores a number of issues associated with demand for assets and global access. The paper looks at operational and political considerations under conditions of battle, as well as the growing area of "military operations other than war"-peacekeeping and humanitarian missions. A study by MITRE [5] describes a model which relates air traffic control events such as take-off, airborne maneuver, and taxi-in, to CNS demand. That study pertains to the National Airspace System in the United States, whereas the study at hand considers Europe and Southwest Asia, in which the variety of countries' airspace rules creates a need for more elaborate scenarios. Finally, an introductory textbook on High Level Architecture (HLA) [6] expounds on the idea of a "federation of 
models." This is a term which has been in circulation for some years; the idea of a linked set of computer models each of which perform specific tasks and together deliver answers to questions of an omnibus nature. Whereas HLA champions real-time, dynamic linkage between "federates," MITRE's approach is looser. We've brought together existing and newly-constructed model elements with static, file-structured data exchange between federates. (Of course, the data exchanged would be dynamic between model runs or cases, as the input and modeling assumptions changed.)

\section{Goals of the Research}

The goals of the study were to identify impacts resulting from non-compliance with CNS/ATM regulations. These impacts were either operational/cost or safety. In discussions with the user community, including former and current military pilots and military air traffic controllers, we determined that looking at operational impacts would carry the greatest weight when focused on war-fighters accomplishing war-time missions. Operational impacts can often be overcome by spending additional money (e.g., for more fuel or more shifts of personnel to accomplish workarounds), but we did not attempt to quantify such costs.

In the first phase of the study, we identified several CNS/ATM impacts on mission operations, including:

- Constrained basing options could require longer flights to operational areas;

- Civilian air traffic control (ATC) could cause operational impacts by delaying or rerouting military flights;

- Flight restrictions (requiring lower flight levels) could cause delay, since traffic generally moves slower at lower altitudes; and

- Delays in strike package formation (e.g., rendezvous of all necessary military aircraft in preparation for the actual strike) could result in missed tasks and wasted resources.

The results from the first phase of the impact analysis illustrated the potential advantage of a modeling approach. Quantitative analysis was limited, but the GANS I-IPT endorsed the thoughtprovoking results. The I-IPT went on to recommend that the team mature its model-based analysis approach by adding greater fidelity, more modeling of interaction with outside entities, and more quantified results. To address the I-IPT's recommendations, our second phase goals were to:

- Improve the granularity of our analysis by looking at specific CNS/ATM capabilities and specific platforms, using the platform-by-platform schedule of implementing these capabilities provided by the GANS CNS/ATM Roadmap for the 2010 and 2015 timeframes;

- Focus on Eurocontrol airspace as one of the most congested, tightly regulated regions in the world, and its vanguard position in traffic and regulation trends;

- Investigate civilian-military interaction, specifically how military flights interact with civilian ATM authorities while transiting civilian airspace en route to operational areas; and

- Investigate Air Combat Command (ACC) fighter interactions with Air Mobility Command (AMC) tankers; specifically, how refueling operations are impacted by mixed CNS capabilities. 
To accomplish these project goals, an analysis team was assembled. The team was drawn primarily from two Federally Funded Research and Development Centers (FFRDCs) within The MITRE Corporation ([7]). MITRE's Center for Advanced Aviation System Development (CAASD, the FAA's FFRDC) brought modeling and analysis expertise in the civilian-managed airspace; and the Center for Air Force C2 Systems (CAFC2S, part of MITRE's DoD FFRDC) brought modeling and analysis experience in the military domain.

\section{Assumptions and Problem Definition}

We reviewed policy related to CNS/ATM capabilities vis-à-vis the USAF use of European airspace for military operations over the coming years. Based on this review, assumptions were developed and a hypothesis was generated to direct the analysis. The assumptions are as follows:

- Traffic will increase. EUROCONTROL forecasts indicate that levels of air traffic will continue to increase over the coming years ([8]). By 2010, overall European air traffic is projected to grow 26\%; by 2015 - 60\%;

- Political considerations will lead to an increasingly regulated environment. Both on the ground and in the air, additional regulations will constrain military air operations. On the ground, airfields near potential conflict areas may deny basing to certain types of military aircraft, perhaps forcing them to remote bases. In the air, diplomatic waivers which today provide airspace for aircraft with lower CNS capabilities will be more difficult or impossible to obtain. In today's environment, lower-CNS-capable flights are accommodated through corridors called Altitude Reservations (ALTRVs). However, in the future, political and economic considerations suggest that ALTRVs will be more difficult or impossible to obtain;

- Initiatives such as Flexible Use of Airspace (FUA) and Single European Sky (SES) will further constrain military operations. These EUROCONTROL and European Union initiatives will further restrict routing options by (1) limiting the availability of Special Use Airspace (SUA) for military operations, and (2) rendering ALTRVs even more difficult to coordinate and reserve; and

- All civil aircraft will be highly CNS capable. Since commercial air carriers benefit financially from being granted the best routes, it is assumed that they will invest in the more robust CNS capabilities. Non-scheduled civil flights are assumed to continue to utilize routes and altitudes.

As a result of these factors, military aircraft will be increasingly required to (1) fly within congested civilian traffic sectors and/or (2) accept less efficient (lower altitudes or longer) routes to mission operation areas. It follows naturally that military aircraft with higher CNS capabilities

will realize benefits from being cleared for more favorable routes of flight. For aircraft with fewer CNS capabilities, uncertainty regarding en route treatment by civil air traffic controllers will result in workarounds and additional contingency planning. Pilots will plan enough time to address worst-case scenarios. As a result, inefficiencies will be inherent in mission plans and in transit routing. (As a short-hand convention, for the remainder of this paper, the terms "capable" and "CNS capable" will mean "enabled to meet the CNS requirements established for the airspace in which the aircraft normally flies." The terms "non-capable" or "non-CNS-capable" will mean that the aircraft's CNS/ATM capabilities do not meet the civil airspace requirements where it normally flies).

The analysis tested several interrelated hypotheses. Overall, military aircraft with a larger set of CNS capabilities are hypothesized to improve mission efficiency for the USAF enterprise 
(including Combat Air Force, Mobility Air Force, and AOC) in an environment that requires use of airspace managed by civilian ATM. More specifically, CNS-capable aircraft may reduce the transit time through civilian-managed airspace and may also reduce the variability in the time of arrival of aircraft in strike packages, resulting in less waiting at the package formation point. This would in turn raise the operations tempo (ops tempo) of the fleet and result in more efficient use of resources, e.g., crews and tankers. In addition, less re-planning of missions due to late arrivals may be required, leaving dynamic planning resources available to address time-sensitive targeting opportunities in the AOC.

The approach for testing these hypotheses was the execution of a "federation of models." Since there are differing requirements for representing differing elements in a simulation context, several modeling capabilities were brought together. Specifically, there are requirements to:

- Model the flight-planning of military flights from forward base to target

- Model civilian air traffic and the associated congestion

- Model the interaction of many military missions throughout a day of civilian traffic

- Model the desired output metrics: ops temp, arrival times, re-planning rate, fuel burn

These models are described in more detail in the Analysis section below.

\section{Civilian Environment and Military Avionics Roadmap}

While there are over two dozen types of CNS/ATM and safety capabilities installed or planned on USAF aircraft, four have received the most attention because of civil aviation authority mandates in Europe, including:

1. $8.33 \mathrm{kHz}$ channel spacing for very high frequency (VHF) voice radios;

2. "FM-immune" navigation receivers that filter out interference from FM radio broadcasts;

3. Mode S transponders that respond to elementary surveillance by ground-based interrogators; and

4. Reduced Vertical Separation Minimum (RVSM) capabilities to maintain $1000 \mathrm{ft}$ vertical separation above flight level 290.

The lack of any of these four capabilities could potentially have adverse impacts for aircraft that fly over Europe. Our approach was to consider which capabilities are planned for installation by 2010 and 2015 in the aircraft that are part of the strike package in the scenarios developed. The basis for this information was a set of CNS/ATM Roadmaps that are updated twice a year by the Air Force sections that own, operate, and modify the aircraft. The Directorate of Operational Capability Requirements (HQ USAF/XOR) maintains the roadmaps. For the study years 2010 and 2015, Table 1 shows the status of the four key capabilities for the aircraft in the scenario strike package. 


\begin{tabular}{|lccccccc|}
\hline Capability & B-52 & E-3 & E-8 & F-15C/D & F-16C & RC-135 & KC-10 \\
\hline 8.33 kHz Radio & P & T & P & P & N & T & T \\
FM Immunity & N & T & T & T & T & T & T \\
Mode S Elementary & N & T & P & P & T & T & T \\
RVSM & N & T & T & N & N & T & T \\
\hline
\end{tabular}

\begin{tabular}{|c|c|c|c|c|c|c|c|}
\hline \multicolumn{8}{|c|}{2015} \\
\hline Capability & B-52 & E-3 & $E-8$ & F-15C/D & F-16C & RC-135 & KC-10 \\
\hline 8.33 kHz Radio & $\mathbf{P}$ & $\mathbf{T}$ & $\mathbf{P}$ & $\mathbf{T}$ & $\mathbf{N}$ & $\mathbf{T}$ & $\mathbf{T}$ \\
\hline FM Immunity & $\mathbf{N}$ & $\mathbf{T}$ & T & $\mathbf{T}$ & $\mathbf{T}$ & $\mathbf{T}$ & $\mathbf{T}$ \\
\hline Mode S Elementary & $\mathbf{N}$ & $\mathbf{T}$ & $\mathbf{P}$ & $\mathbf{T}$ & $\mathbf{T}$ & $\mathbf{T}$ & $\mathbf{T}$ \\
\hline RVSM & $\mathbf{N}$ & T & $\begin{array}{ll}T \\
\text { t }\end{array}$ & $\mathbf{N}$ & $\mathbf{N}$ & $\begin{array}{ll}T \\
\end{array}$ & $\mathbf{T}$ \\
\hline N No Capabili & $\mathbf{F}$ & Part & et $\mathrm{C}$ & bility & $\begin{array}{lll}T \\
\end{array}$ & Total Flee & Capability \\
\hline
\end{tabular}

Table 1: CNS/ATM Capabilities on Scenario Strike Package Aircraft

The $8.33 \mathrm{kHz}$ radio and FM Immunity (FMI) capabilities were European mandates in 1999 and 2001; therefore most USAF aircraft have already been modified with the necessary systems. However, note that the F-16 fleet still does not have $8.33 \mathrm{kHz}$ radios, and the B-52, E-8, and F-15 programs have modified only parts of their fleets. The current exemptions may expire soon, so one goal of the study is to quantify the impacts of continued non-compliance with respect to these two capabilities. We are primarily concerned with the red cells (no capability), because when a fleet is partially compliant, only aircraft that already have the European-required capabilities are typically sent on missions that involve flight over Europe.

Some further explanation is in order for the capabilities we chose not to model; namely, Mode S and RVSM. A Mode S transponder that permits a capability known as Elementary Surveillance is a European requirement after March 2009. Without Mode S, aircraft will not be permitted to fly over the core of Europe; hence most USAF aircraft have plans to comply. For the B-52 fleet, both Mode S and FMI carry no-fly implications. This means the impact of non-compliance would be the same regardless of which capability is missing, because B-52s would have to fly around Europe in either case. Therefore, we modeled only FMI non-compliance impacts on the B-52, since the study results could also be used to show the impacts of not equipping B-52s with a Mode S transponder.

RVSM, started in the North Atlantic in 1997, became a European requirement in 2001, and has now spread to most of the world. It has added six new flight levels and more air traffic capacity by reducing vertical spacing from $2000 \mathrm{ft}$ to $1000 \mathrm{ft}$ between FL290 and FL410 (spacing below FL290 was already at $1000 \mathrm{ft}$. vertical). Unfortunately, the equipage for RVSM, which enables more accurate altitude-keeping, takes up too much space in fighters and is technically incompatible with the various configurations of their "external stores," (externally mounted bombs and other weapons) because of aerodynamic effects on the altitude sensors. No fighters except the new Joint Strike Fighter have plans to add RVSM capability. We did not model the impacts of RVSM non-compliance because state aircraft are currently exempt from the requirement and can also stay below RVSM airspace if necessary. In addition, it would be unproductive to calculate the benefit of allowing fighters to fly unrestricted above FL290, since RVSM capabilities on fighters have little chance of being installed. Note that the B-52 fleet also lacks RVSM, but the impacts of not having FMI and Mode S dominate the RVSM deficiency. The B-52 program has plans to request funds for RVSM in its FY08 budget. 
The only difference between 2010 and 2015 is that F-15C/D will complete its installation of 8.33 $\mathrm{kHz}$ and Mode S by 2015. Only part of the fleet has these capabilities in 2010.

In summary, $8.33 \mathrm{kHz}$ radios on fighters and FMI on B-52 were chosen as the CNS/ATM capabilities to analyze in this study. The simulations were run with and without these capabilities onboard, in order to assess their impacts. Table 2 describes these capabilities in more detail and lists the exemptions and workarounds that allow aircraft to fly without the capabilities.

Table $2-8.33 \mathrm{kHz}$ and FMI Requirements and Workarounds

\begin{tabular}{|c|c|c|}
\hline & 8.33 kHz VHF Radio & FM Immune Navigation Receiver \\
\hline Authority & $\begin{array}{l}\text { European Organisation for the Safety of } \\
\text { Air Navigation (EUROCONTROL) }\end{array}$ & $\begin{array}{l}\text { International Civil Aviation } \\
\text { Organization (ICAO) }\end{array}$ \\
\hline Description & $\begin{array}{l}8.33 \mathrm{kHz} \text { voice radios increase the } \\
\text { number of voice channels available } \\
\text { between pilots and air traffic controllers } \\
\text { by dividing the old } 25 \mathrm{kHz} \text { channels } \\
\text { into thirds. EUROCONTROL's } 8.33 \\
\text { program was first implemented in 1999, } \\
\text { and the coverage area and altitude range } \\
\text { have been increasing in phases. The } \\
\text { next phase ("vertical expansion") in } \\
2007 \text { will lower the minimum altitude } \\
\text { from FL } 245 \text { to FL195. }\end{array}$ & $\begin{array}{l}\text { Interference from commercial FM } \\
\text { radio broadcasts can cause misleading } \\
\text { indications on older } \\
\text { navigation/landing receivers, which } \\
\text { use a frequency band just above the } \\
\text { FM radio band. This is a safety issue } \\
\text { because pilots may be misled to } \\
\text { believe they're on the correct course } \\
\text { or approach when they're actually not. } \\
\text { "FM immune" receivers with better } \\
\text { filters solve the problem. }\end{array}$ \\
\hline $\begin{array}{l}\text { Coverage } \\
\text { Area }\end{array}$ & $\begin{array}{l}30 \text { Countries in the European Civil } \\
\text { Aviation Council (ECAC) }\end{array}$ & $\begin{array}{l}51 \text { Countries in the ICAO European } \\
\text { Region }\end{array}$ \\
\hline $\begin{array}{l}\text { Mode of } \\
\text { Flight/ } \\
\text { Altitude }\end{array}$ & $\begin{array}{l}\text { 1. En Route above FL245 (now) } \\
\text { 2. En Route above FL195 (after } \\
\text { “vertical expansion”) }\end{array}$ & $\begin{array}{l}\text { 1. En Route Navigation at all altitudes } \\
\text { using ground-based VHF } \\
\text { Omnidirectional Range (VOR) } \\
\text { transmitters } \\
\text { 2. Approach and Landing using } \\
\text { Instrument Landing System (ILS) }\end{array}$ \\
\hline $\begin{array}{l}\text { Compliance } \\
\text { Date }\end{array}$ & 12 March 2009 (state aircraft) & 1 January 2001 (all aircraft) \\
\hline Exemptions & $\begin{array}{l}\text { Currently State aircraft may use UHF } \\
\text { radios for pilot/controller voice } \\
\text { communications in lieu of } 8.33 \text { if UHF } \\
\text { coverage is available. However a } \\
\text { revised EUROCONTROL policy, still } \\
\text { in draft, states that "the carriage of } 8.33 \\
\text { kHz radios applies to all State aircraft } \\
\text { from } 12 \text { Mar 09.” Noncompliance } \\
\text { would be limited to exceptional } \\
\text { circumstances. }\end{array}$ & $\begin{array}{l}\text { Since 2000, USDoD has annually } \\
\text { negotiated bi-lateral waivers with all } \\
51 \text { countries, granting permission for } \\
\text { USDoD aircraft to use means of } \\
\text { navigation and landing other than } \\
\text { VOR and ILS. Countries are growing } \\
\text { weary of granting these waivers. }\end{array}$ \\
\hline
\end{tabular}




\begin{tabular}{|l|l|l|}
\hline $\begin{array}{l}\text { Operational } \\
\text { Work- } \\
\text { Around }\end{array}$ & $\begin{array}{l}\text { Fly below FL195 using 25kHz radio, or } \\
\text { fly around the } 8.33 \text { coverage area. }\end{array}$ & Fly around the FMI coverage area. \\
\hline
\end{tabular}

\section{Scenario Development}

The application of simulation modeling requires a specific scenario in which to represent assumptions and test hypotheses. Global strike (stealth fighter attack missions) and global mobility (humanitarian missions) concepts were considered before focusing on the global response concept. In a global response concept, Combat Air Force (CAF) assets are deployed from U.S. bases to forward operating locations (FOL) for employment in the operational area. The global response concept fits well with our impact analysis needs because of the mix of platforms and the inherent interaction between CAF and Mobility Air Force (MAF). The ACC from Langley AFB ([9]) kindly provided an unclassified deploy/employ scenario that identified numbers and types of CAF platforms, as well as basing at the appropriate FOL. Note: for this impact analysis study, only the employment phase (forward base to target) was considered. Using the ACC-supplied numbers and types of aircraft, the simulation scenario could be laid out in detail.

By 2010, four aircraft types were identified that would be affected by the lack of CNS/ATM capability: the B-52 bomber and the F-15C, F-15D, and F-16C fighters. The B-52 bomber was projected to lack FMI, and the fighters were projected to lack 8.33 Communications. Note that the fighters cannot meet the RVSM capability due to space and ordinance limitations, as explained above. Both FMI and 8.33 Communications are required throughout Europe. Basing locations for fighters on the continent were Italy, Macedonia, and Hungary (Eastern Europe), all of which are very close to the edge of the 8.33 and FMI capability area. Scenario 1 was selected as the worst case due to diplomatic and operational considerations; all fighters are based in the United Kingdom. Scenario 2 has the fighters coming from the ACC-provided bases in Italy, Macedonia, and Hungary. In both scenarios, the B-52 is based in the United Kingdom, as provided by the ACC.

The routes for the capable and non-capable fighter cases follow from the 8.33 communications and RVSM regulations: 8.33 capable aircraft can fly up to flight level 290 (RVSM constraint) and the 8.33 non-capable aircraft must fly below flight level 195. The route for the capable and noncapable bomber cases follow from FMI - the capable route is optimally through the FMI area and the non-capable route is around the FMI area. The non-capable B-52 bomber route is around the FMI airspace in both scenarios (bases in the UK and Eastern Europe). A large target, such as an airfield, was selected in Southwest Asia with a package formation or marshalling point just off the west coast of Syria in the Mediterranean Sea. For this target, one B-52, two F-15Cs, four F15Ds, and four F-16Cs were deployed with the fighters flying in formation. In addition, specialty aircraft (E-3, E-8, RC-135) and tankers (KC-135) were also a notional part of the analysis, but were not directly included.

An unclassified Air Tasking Order (ATO), similar to the first day of the Desert Storm campaign in 1991, was used to complete the scenario. (It was generated using the campaign model Thunder [10]). This ATO contained 446 missions. This mission planning, combined with an assumption of a strike-package of 11 flights (one bomber and 10 fighters, not counting tankers or specialty aircraft) yielded the necessary detail for the simulation modeling. The day-long file of 446 missions was divided into 4 time periods corresponding to waves of peak activity. 


\section{Analysis Process}

The analysis of the two scenarios was identical and was performed in five steps:

1. Military routes were generated;

2. Military routes were overlaid on civilian air traffic and the flight time was simulated;

3. Distributions for the estimated time of arrival for each aircraft was determined by introducing variability with respect to congestion, refueling time, and weather;

4. The estimated time of arrival for each aircraft or formation was used to estimate the average time for package formation; and

5. The effect of missed packages on the AOC was determined.

These five steps are described in detail in the following subsections of the paper. Figure 1 is a schematic of these steps, naming the tools employed plus the information inputs and outputs.

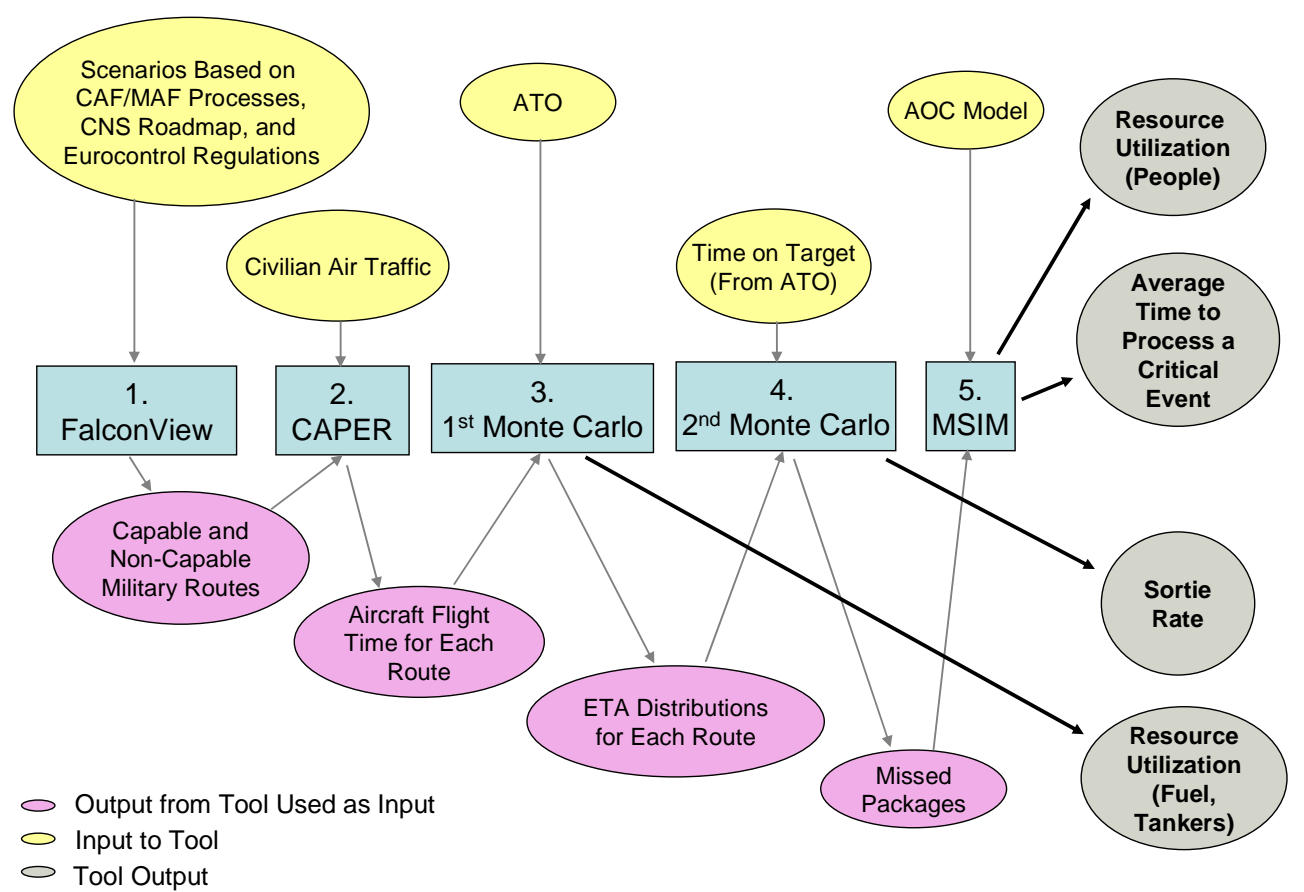

Figure 1: Steps of Analysis and Tools Used In This Study (shown in blue rectangles)

\section{Analysis Step 1: Military Route Generation}

The first step in the analysis process was to plan detailed flight paths for each of the aircraft in the defined strike package. Example routes were obtained from the Global Decision Support System (GDSS) database that the Air Force Research Laboratory maintains, which contains global military flight plans in civilian airspace. The GDSS routes were altered based on constraints imposed by the presence (or absence) of particular capabilities. Two routes were planned for each aircraft: routes based on operational workarounds resulting from capability shortfalls, and routes based on full capability.

We used a software package called Portable Flight Planning Software (PFPS) to design the routes for this analysis. PFPS is a suite of software tools running on a Microsoft Windows platform and 
is part of the Air Force Mission Support System (AFMSS). PFPS provides a set of common aviation planning tools that support a broad range of mission planning needs and operational environments. The system is capable of supporting planning for the following missions: air-to-air, air-to-ground, air refueling, electronic combat, reconnaissance, special operations, conventional gravity weapon release, airlift, and rescue.

For this analysis, two components of PFPS were used: Combat Flight Planning System (CFPS) and FalconView. CFPS provided extensive route editing and planning functions, a set of detailed flight dynamics models for military aircraft, and access to the Digital Aeronautical Flight Information File (DAFIF) database. FalconView provided a map-based graphical user interface, overlay and display capabilities, and drag-and-drop editing. The routes designed can be exported in either a native binary format or an XML-based format.

The selected routes represent preferred routing, in which a direct great circle path from the take off point to the destination is used. In all cases, our destination was the marshalling point, at an air navigation waypoint in the eastern Mediterranean Sea. The aircraft were assumed to depart from various locations as detailed in Table 3. For cases that assumed full capability, the routes were created at nominal altitudes and airspeed (as suggested by the planning tools). In cases where the fighters were assumed to lack the required 8.33 communications equipment, the aircraft were required to fly at a lower altitude but were allowed to ascend to a better altitude once they left the 8.33-restricted area. In the case where the B-52 lacked FMI capability, the aircraft was allowed to depart the UK, but had to immediately leave the FMI-restricted area and circumnavigate the Iberian Peninsula (Spain and Portugal), enter the Mediterranean Sea through the Straits of Gibraltar, and fly over water to the marshalling point. The route paths for Scenario 1 and 2 are shown in Figures 2 and 3, respectively. The B-52 options are the same in both scenarios.

Table 3: Aircraft, Base (Destination BALMA), and Capability Shortfall and Workaround for Scenario 1 and 2.

Scenario 1: Fighters Based in United Kingdom

\begin{tabular}{|l|l|l|}
\hline Aircraft & Base & Capability Shortfall and Workaround \\
\hline F-15D & $\begin{array}{l}\text { EGUN - } \\
\text { Mildenhall }\end{array}$ & 8.33 Communications: Fly below FL195 in restricted areas \\
\hline F-15C & $\begin{array}{l}\text { EGUN - } \\
\text { Mildenhall }\end{array}$ & 8.33 Communications: Fly below FL195 in restricted areas \\
\hline F-16C & $\begin{array}{l}\text { EGVA - } \\
\text { Fairford }\end{array}$ & 8.33 Communications: Fly below FL195 in restricted areas \\
\hline B-52 & $\begin{array}{l}\text { EGVA - } \\
\text { Fairford }\end{array}$ & FM Immunity: Avoid restricted airspace \\
\hline
\end{tabular}

Scenario 2: Fighters Based in Eastern Europe

\begin{tabular}{|l|l|l|}
\hline Aircraft & Base & Capability Shortfall and Workaround \\
\hline F-15D & $\begin{array}{l}\text { LWSK - } \\
\text { Skopje }\end{array}$ & 8.33 Communications: Fly below FL195 in restricted areas \\
\hline F-15C & $\begin{array}{l}\text { LHBP - } \\
\text { Budapest }\end{array}$ & 8.33 Communications: Fly below FL195 in restricted areas \\
\hline F-16C & LIPA - & 8.33 Communications: Fly below FL195 in restricted areas \\
\hline
\end{tabular}




\begin{tabular}{|l|l|l|}
\hline & Aviano & \\
\hline B-52 & $\begin{array}{l}\text { EGVA - } \\
\text { Fairford }\end{array}$ & FM Immunity: Avoid restricted airspace \\
\hline
\end{tabular}

These routes were sufficiently long that, in most cases, the fighter aircraft did not have sufficient range to fly from takeoff to the marshalling point without refueling. The lone exception was the F-15D in Scenario 2, which was based sufficiently close to the area of operation (AOR) that no en route refueling was necessary. Air refueling tracks were assumed available as needed (Table 4). Note that all aircraft are refueled at the marshalling point before the actual strike is undertaken, including loitering aircraft if applicable (e.g., package formation delayed).

The en route fixed air refueling was modeled by having the aircraft fly to a pre-defined waypoint where a tanker aircraft was available. At this point, the fighter descended to FL250 (unless it was flying in an 8.33 restricted area, in which case it maintained its lower altitude). The fighter then entered a loitering orbit for a fixed amount of time. Based on conversations with subject matter experts ([11]), it was assumed that a four-flight formation would require an average of 60 minutes (with minimum and maximum at \pm 15 minutes) to refuel and a two-flight formation would require an average of 30 minutes (with a minimum and maximum at \pm 10 minutes) for refueling.

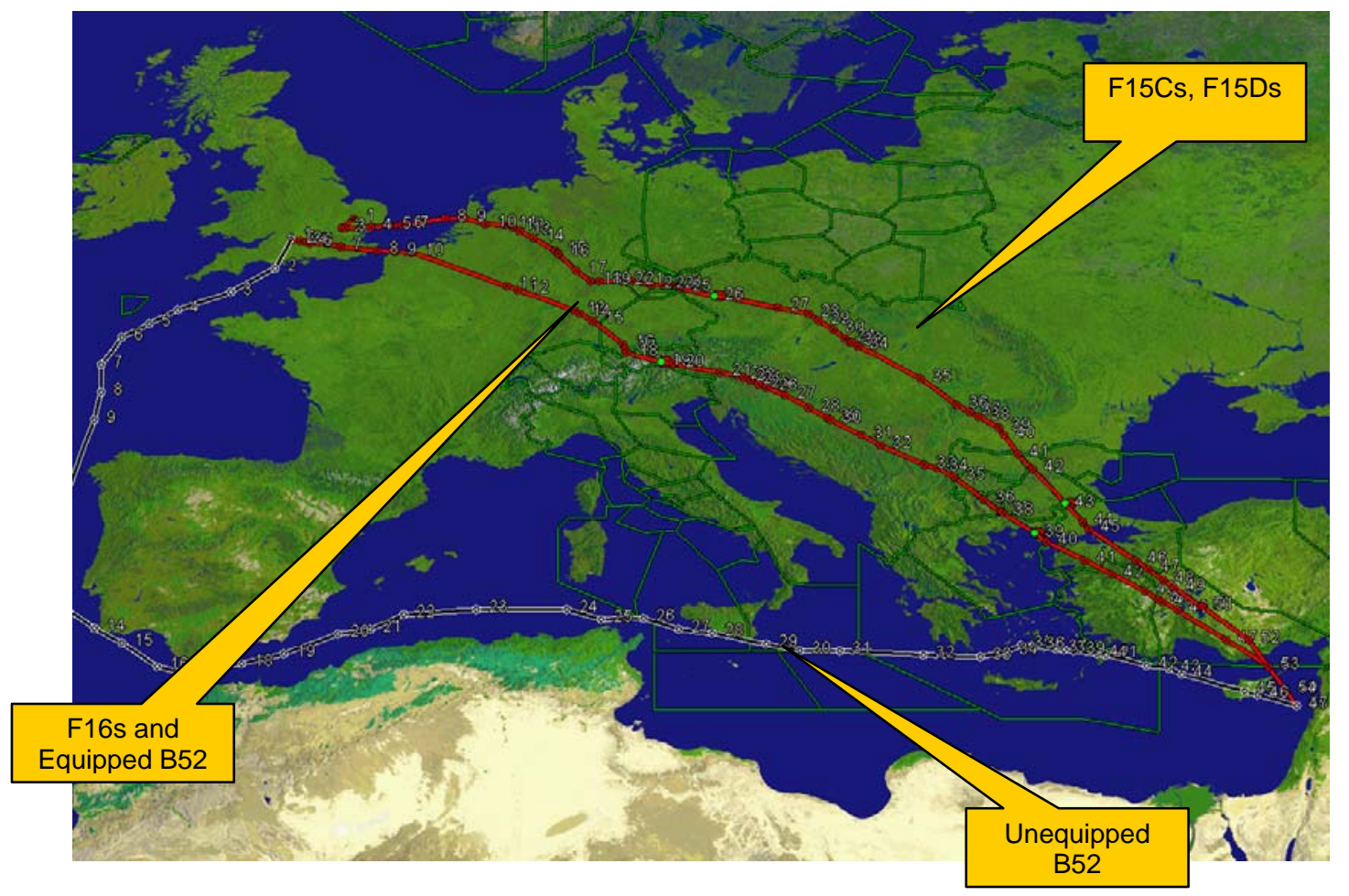

Figure 2: Routes for Scenario 1 - United Kingdom-Based Fighters 


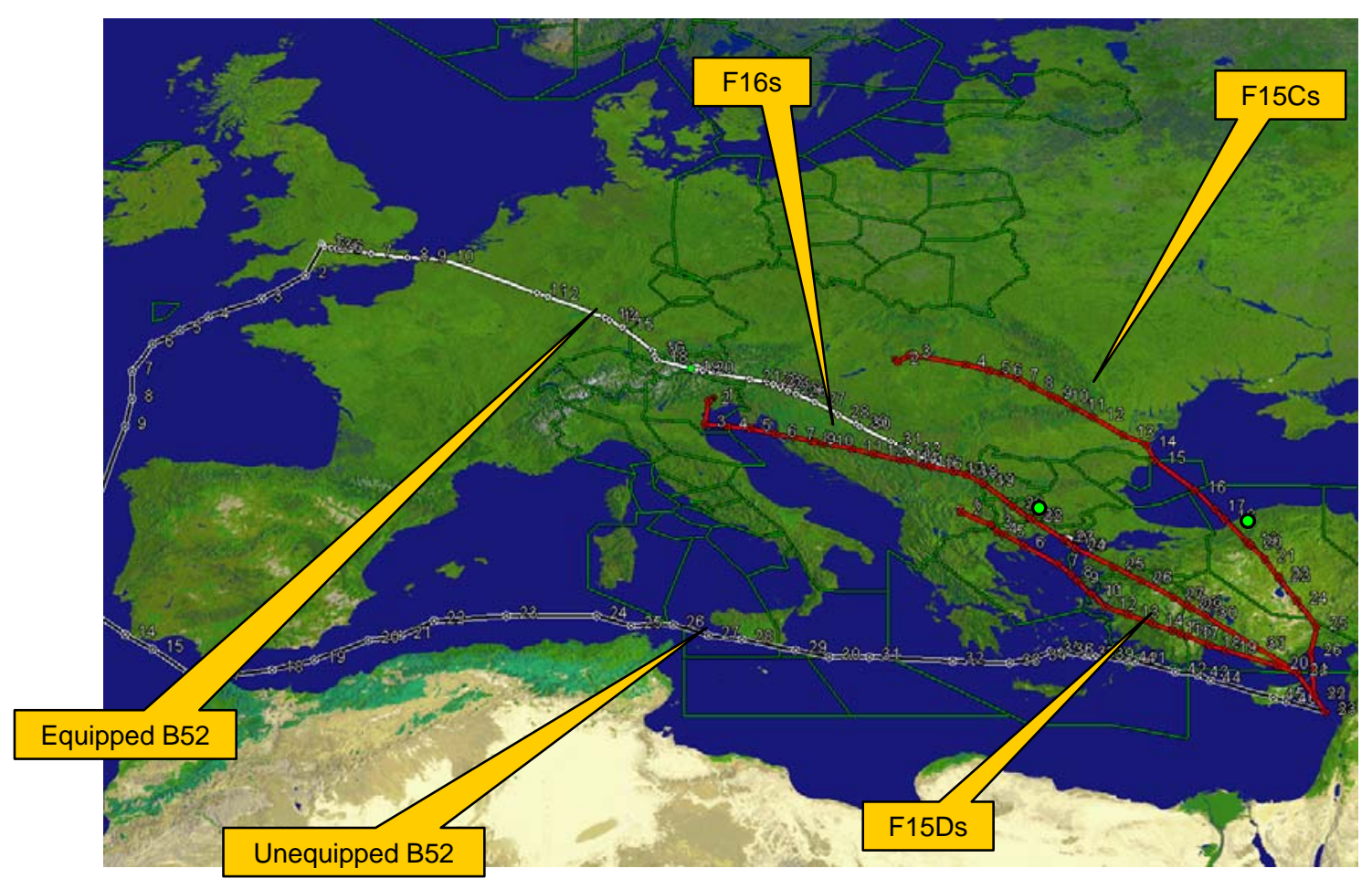

Figure 3: Routes for Scenario 2 - Eastern European-Based Fighters

Table 4: Air Refueling Tracks Used in Scenarios 1 and 2

\begin{tabular}{|c|c|c|}
\hline \multirow{2}{*}{ Scenario } & Waypoint & Aircraft Supported \\
\hline \multirow{2}{*}{ \#1, UK-Based } & ROKEM & F-15D \\
& ADORU & F-16C \\
& LIZUM & F-15D \\
& DIKLO & F-16C \\
& BALMA & All Aircraft \\
\hline \multirow{2}{*}{ \#2 European-Based } & BUMRU & F-15C \\
& BANSO & F-16C \\
& BALMA & All Aircraft \\
\hline
\end{tabular}

In Scenario 2, a "fighter drag" case was modeled in which the fighters were accompanied by a KC-10 tanker, which compensates for the 8.33 communications capability shortfall (e.g., the tanker is capable and its CNS capabilities are utilized to lead the aircraft formation). In this case, the refueling is accomplished in a moving track while continuing to make forward progress toward the destination. In order to accomplish refueling in this fashion, the aircraft must slow to 310 knots (nautical miles per hour) true airspeed for the duration of the refueling operation. Military flight route definitions were exported for use in Step 2, as described below. 


\section{Analysis Step 2: Military Routes in Civilian Traffic and Estimation of Flying Times}

The CAASD Analysis Platform for En Route (CAPER) was used as a simulation platform to model the civilian traffic and military flights in order to estimate flying times for the mission. CAPER is a modeling and analysis capability derived from a prototype which was used for development of new flow control concepts for the Federal Aviation Administration. Some of CAPER capabilities include:

- Visualization of current and future traffic flows and sector loading;

- Identification of flights that are expected to be directly impacted by the situation;

- Defining candidate re-routes to alleviate the situation; and

- Analyzing the impact of a reroute strategy on sector loading for all the sectors.

CAPER was originally developed to work within the confines of the Continental United States (CONUS), and in order to use CAPER for this analysis, CAASD obtained and modeled the following data for the European airspace and flight operations:

- Actual European traffic data;

- Commercial airline schedule data from the Official Airline Guide (OAG);

- European adaptation data (e.g., fixes, airways, sector definitions, and Geo-political boundaries); and

- Wind data (for accurate trajectory modeling).

To simulate an accurate representation of the European civilian traffic, MITRE contracted with an Italian company (A.S.A. Srl, for information, [12]) to generate the flight plan data for 3 specific days in June 2005. The data took into account the actual routes that were previously flown between individual city pairs and restricted airspace. This combination of input provided a realistic scenario of the civilian air operations on those days. Additionally, CAASD used actual European traffic data obtained from EUROCONTROL for the same days to validate the data generated by A.S.A. Srl. CAASD also extracted additional information from the EUROCONTROL data, which included non-scheduled traffic (called "General Aviation" in the United States). Military traffic data from the FalconView flight planning system was also added. CAASD obtained the necessary adaptation data including sector definition data in order to accurately count aircraft traversing individual sectors and to compute sector capacities (for details on sector capacities, [13]). Using EUROCONTROL growth estimates [8], civilian traffic was increased to approximate 2010 and 2015 levels.

The complete scenario, including flight plans and aircraft position reports (for both civilian and military flights), wind data, and adaptation data were then modeled by CAPER for a 24-hour period, resulting in 4-D trajectories for all aircraft flying during that period. The key outputs from this step were the expected time of arrival (ETA) for each of the USAF aircraft in the military scenarios. Figure 4 depicts, for a single point in time, the CAPER traffic display with all airborne civilian aircraft depicted. This particular example demonstrates the CAPER future traffic display feature, which allows the user to project the traffic to the future. As a zoom-in to an area of interest, Figure 5 shows military routes overlaying the civilian traffic. The rectangular loops on the military routes are the holding patterns where refueling takes place. 


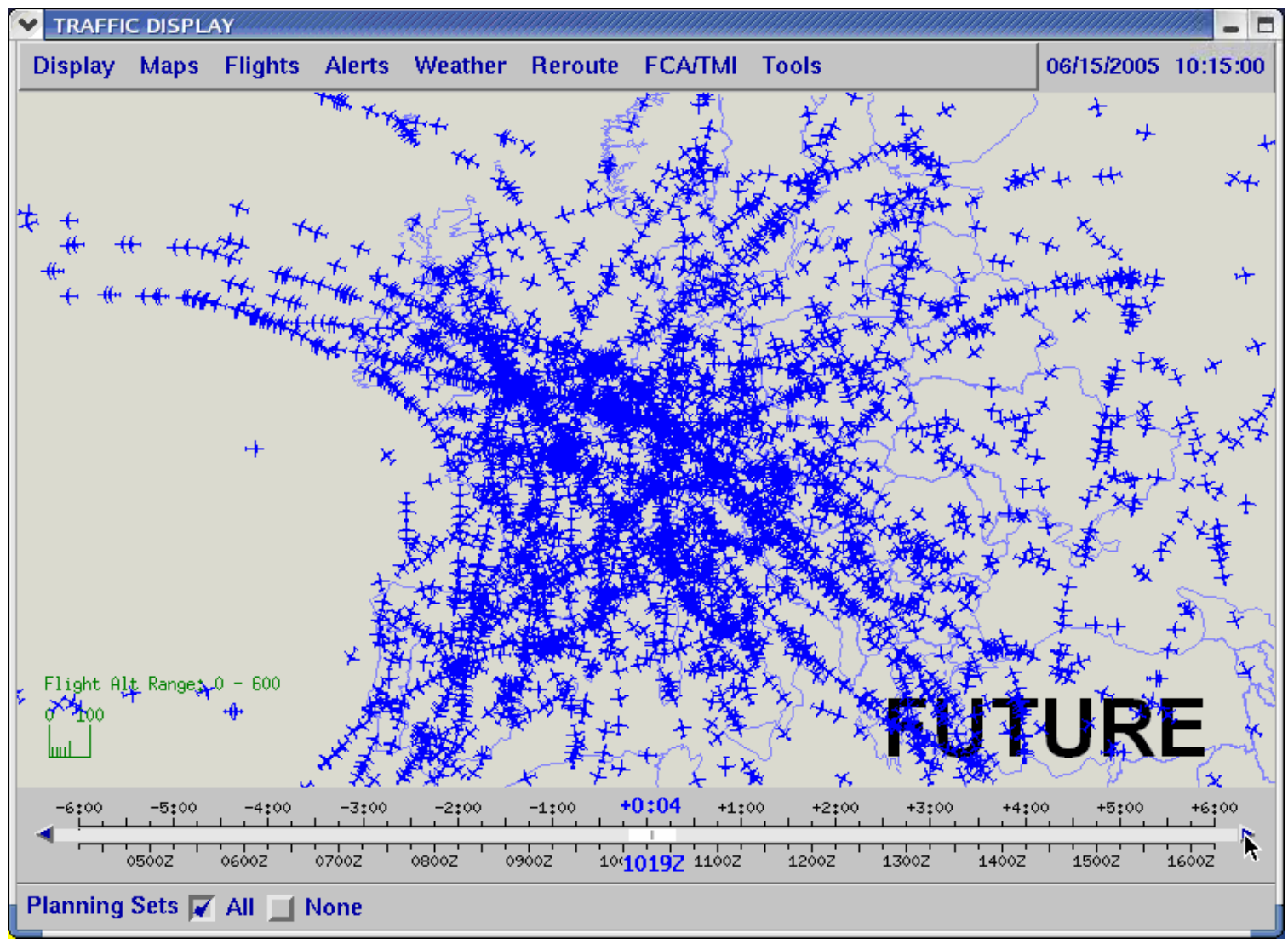

Figure 4: CAPER Traffic Display for Europe

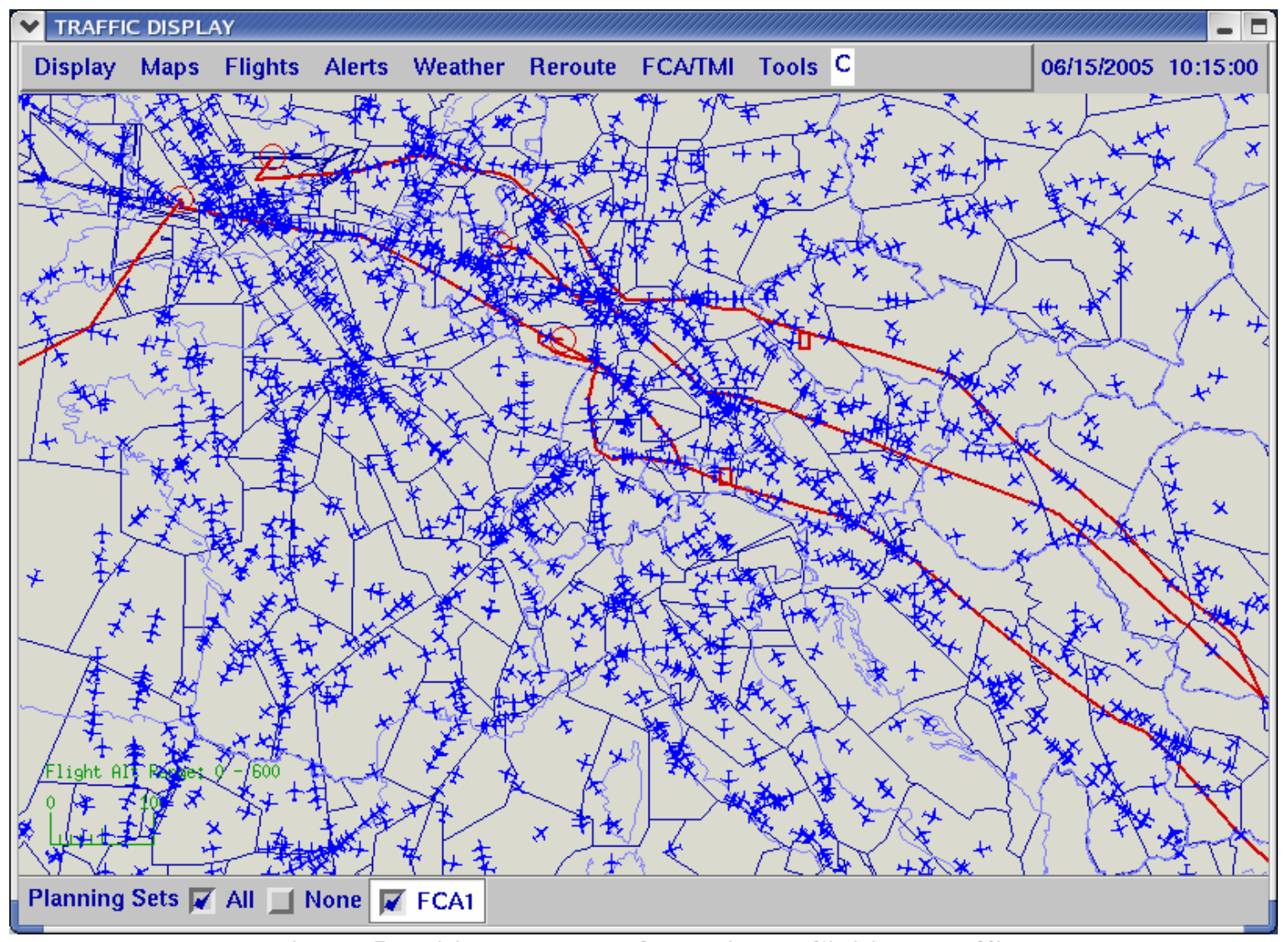

Figure 5: Military Routes Overlaid on Civilian Traffic

Analysis Step 3: Generating Distributions of ETA 
The times of arrival for each formation obtained from CAPER were run through a Monte Carlo process. The nominal modeled time of arrival was varied randomly by sampling from distributions of delay times for civilian air traffic congestion, refueling time, and en route weather.

The distribution for civilian air traffic congestion was formulated offline by several team members playing the role of traffic managers, and rerouting traffic around sectors using the CAPER dynamic rerouting capability. A sample of about 30 reroutes were performed, and those 30 observations (additional flying times) were fit to a triangular distribution. In the Monte Carlo process, the times and places of civilian congestion were modeled, using equations from [13], and compared to the nominal military flights' sector penetration times. When the two coincided, a randomized draw was made from the distribution, to simulate the additional time associated with the military flight being rerouted around a congested sector.

The refueling delays were also modeled as triangular distributions, using the mean times per subject matter experts, and then assuming \pm 10 minutes as a range around the 30 -minute-mean distribution, and \pm 15 minutes range around the 60-minute-mean distribution. For the (assumed triangular) distribution of delay associated with severe en route weather, arrival delay data from a bad weather day in the U.S. were used. The data was taken from flights with a distance comparable to the UK to Syria distance used in Scenario 1.

Triangular distributions were used as an expedient, since it was reasonable that a central probability mass existed between two diminishing-probability tails. For sufficient representation of the variability, 100 realizations were created for each of the 446 missions, multiplied by 11 flights per mission. This data was further processed, see below, to generate strike package formation estimates.

\section{Analysis Step 4: Estimating Package Formation Times}

The estimated time of arrival distributions obtained for each aircraft formation (formations of aircraft were treated as a single distribution) were used to determine the delay in overall package formation time. The arrival distributions for the four aircraft types, B-52, F-15Cs, F-15Ds, and F16Cs, were approximately aligned by selecting appropriate take-off times, so that the tails on the right-hand side of the distributions coincided with the mission's time-on-target per the ATO. The take-off times were parameterized to vary the number of missed packages. A Monte Carlo process was used to calculate random time of arrival based on the four distributions. From this, the average time of waiting for the last set of aircraft to arrive, the event "package formation complete," was calculated.

\section{Analysis Step 5: Effect of Missed Strike Packages on Air Operations Center Performance}

An analysis was performed to determine the effect of missed packages on the Air Operations Center (AOC) in terms of critical event response time and increase in required personnel. A detailed model of the operational architecture of the AOC was used for this analysis. The model was developed using the MITRE-MSIM tool, a simulation tool used to model the performance of distributed architectural systems. Using MSIM, we graphically specified the architecture of the AOC using a Colored Petri Net (CPN). For this model specification and work-load scenario, MSIM produced performance metrics such as component utilization, component throughput, and 
thread response time. This AOC operational model was based on staffing levels taken from an unclassified 2001 AOC Manpower Reduction Study [14].

The input to the model included six different types of events: Theatre Ballistic Missile (TBM) launch, TBM Detection, Combat Search and Rescue (CSAR, a "pilot down” situation), Surface to Air Missile (SAM) Radiate, Choke Point, and ATO re-tasking. The ATO re-tasking event represents missed packages that were caused by delays resulting from CNS non-equipage issues. All events were given the same priority, with the exception of a CSAR event, which was given a higher priority. The effect of this was that the higher priority event preempted work on any other event type. These decisions were made based on conversations with subject matter experts who had worked in an operational AOC and had observed current exercises of new equipment and procedures being developed for the AOC.

\section{Results}

Final results for this study are presented here, in terms of times of arrival for capable vs. noncapable scenarios, strike package formation time, the effect of missed packages on AOC, and fuel utilization between capable and non-capable packages.

\section{Arrival Times}

The time of arrival distributions for the capable and non-capable F-15C aircraft are shown in Figure 6 for the UK bases in both the 2010 and 2015 timeframes. The fourth time period is shown, since the congestion was highest during this period. The CNS capable aircraft arrives much faster in both the 2010 and 2015 timeframes (72 and 74 minutes, respectively). However, there is not much difference between them. The spread in the time of arrival distributions is also lower for the CNS capable aircraft in both the 2010 and 2015 timeframes. These results align with our hypothesis for CNS capable aircraft arriving faster and with less variability in the time of arrival distributions.

The mission times for the capable, non-capable, and drag are shown in Figure 7 for four different base locations. The (pink bar is the average time of arrival from the Monte Carlo-modeled distributions, as shown in Figure 6. Error bars indicating two standard deviations are given to indicate the spread of the distributions. Similarly, the green bar is the average return flight time on the same path. The arrival and return flight times were determined at different times of day. The red bar is the time to get from the package formation point to the target and the time to carry out the mission - this is assumed constant in this analyses. The yellow bar indicates the package formation time. This value was determined using the distributions for the bomber and 3 fighter formations to estimate an average time for package formation. The figure shows the effect of base location on the mission time and relative sortie rate for the CNS capable and non-capable packages, as well as the non-capable drag for the bases in Eastern Europe. The bases in Eastern Europe show a relatively small (0-4\% difference in sortie rate) effect since those locations are on the edge of the 8.33 area (map in Figure 7). The bases in the UK indicate the largest (15\% difference in sortie rate) effect, in which all aircraft fly from the UK to a target in Southwest Asia. The results of this study can be used to determine the impacts of CNS/ATM shortfalls on mission sortie rates, given a forward-basing location in Europe. 
Non-Capable: 435 minutes, 134 spread CNS Capable: 363 minutes, 107 spread
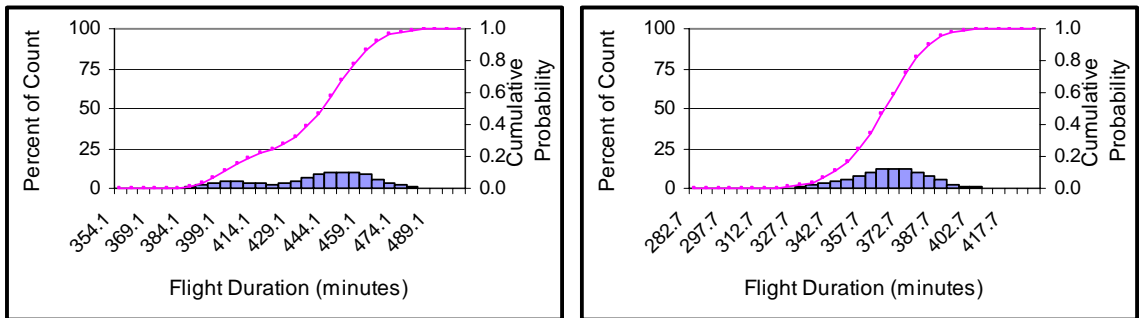

CNS Capable: 72 minutes faster and 27 minutes less spread

Non-Capable: 451 minutes, 145 spread

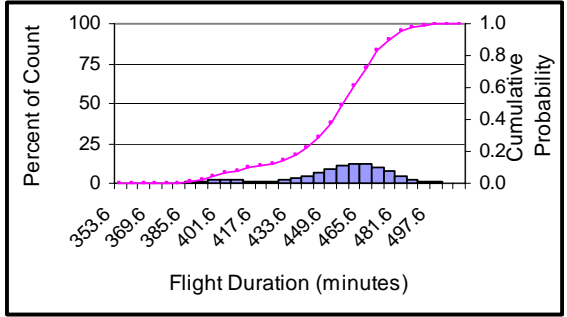

CNS Capable: 377 minutes 133 spread

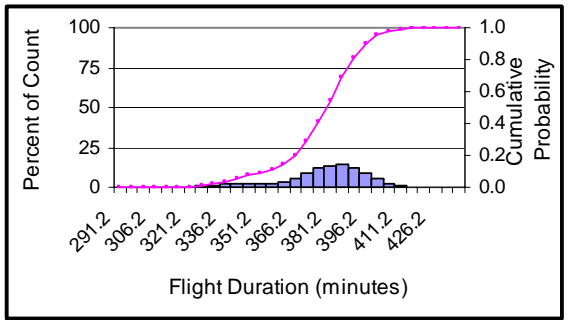

CNS Capable: 74 minutes faster and 12 minutes less spread

Figure 6: Capable and Non-Capable Estimated Time of Arrival Distributions for the F-15C in 2010 and 2015

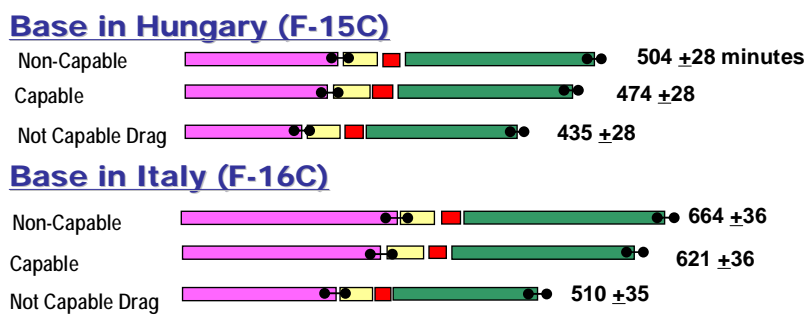

Base in Macedonia (F-15D)
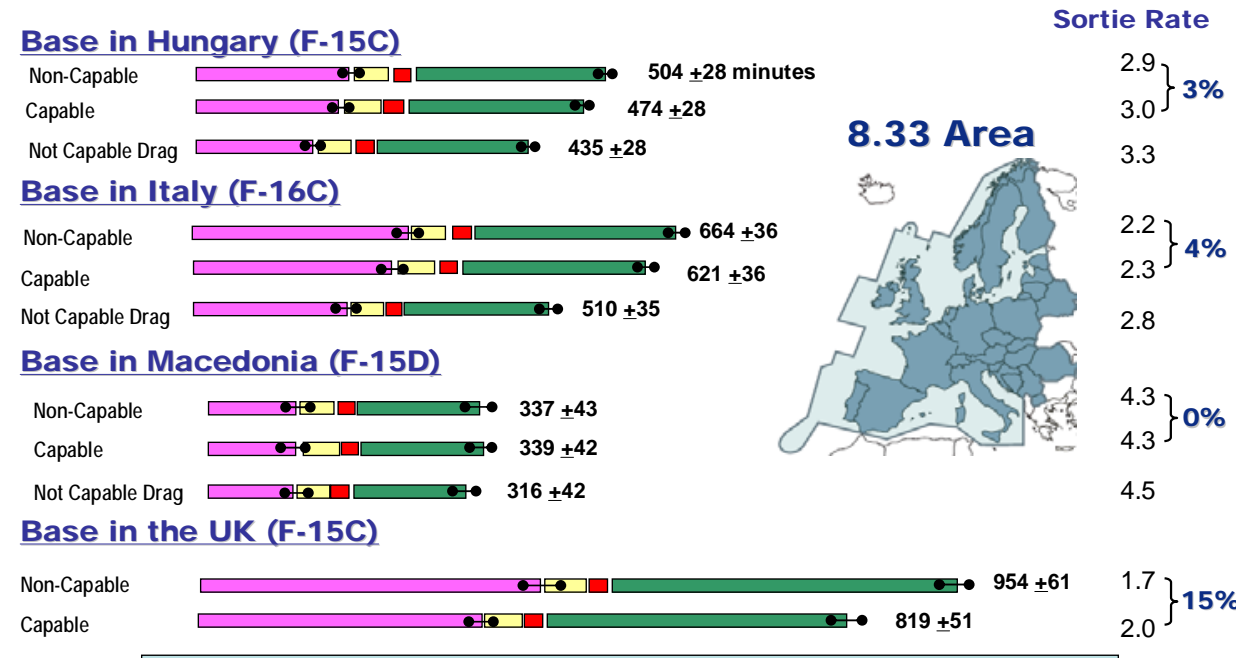

$\left.\begin{array}{l}1.7 \\ 2.0\end{array}\right\} 15 \%$

$\because 2 \sigma \quad$ In Transit, Waiting at Marshaling Point Completing Attack Phase, Return

\section{Figure 7: Arrival Times for Capable and Non-Capable Aircraft for Four Base Locations}

It was initially thought that the variability in arrival times for the B-52 and three fighter packages, the yellow bar, would cause a trade-off between AOC response time and sortie rate. However, the degree of variability (less than 1 hour) turned out to be too small with respect to the overall time of flight ( $\sim 7$ hours from the UK) to affect sortie rate significantly. Hence, a pilot could leave a little earlier to minimize the effect in the AOC and not affect the sortie rate significantly. 


\section{Response Time for Re-Planning}

An analysis of the results from the MSIM AOC simulation runs (Figure 8) showed that for every 10 packages missed, the average time to process any TST event increases by one hour. Our AOC subject matter experts [15] estimated based on their individual experience, a success rate for strike package formation of between $95 \%$ and $98 \%$. On a 500 mission day, that is a miss rate of $2 \%$ to $5 \%$, or 10-25 failed packages. Separately, another subject matter expert [16] confirmed that 10 failed packages was conservative. Therefore, given these experiences and analysis results, a minimum increase in processing time of 1.0-2.5 hours (1 hour for 10 and 2.5 hours for 25 ) would be incurred.

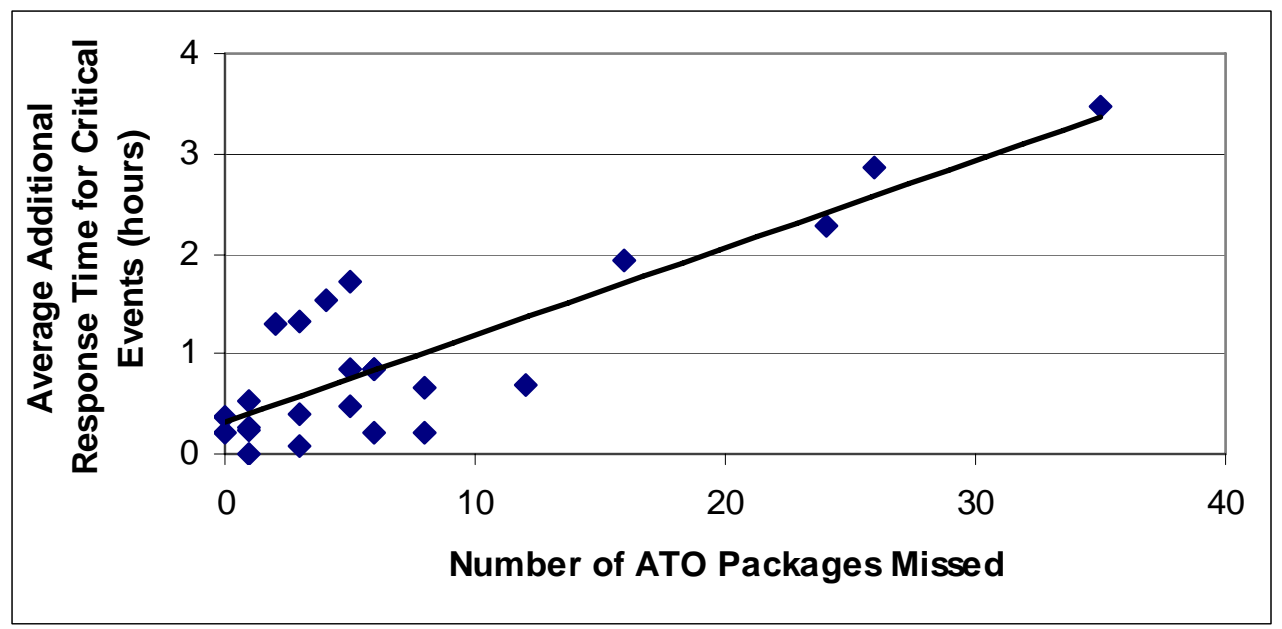

Figure 8: Additional Response Time as a Function of ATO Strike Packages Missed

\section{Tanker Utilization}

Mission tanker utilization is an important consideration in light of logistical and budget constraints. The CFPS, which was used to plan the routes, includes a detailed flight performance model for each aircraft type, including fuel utilization. However, further simulation modeling via CAPER and Monte Carlo sampling estimated increased flying time beyond the CFPS flight planning, because of delay caused by civilian air traffic congestion. Since the fuel consumption is relatively constant with respect to time (given a particular engine setting), and since most of the flight duration was spent at a cruise setting, we adjusted the fuel consumption computed by CFPS by the ratio of the duration computed by our CAPER/Monte Carlo analysis to the baseline duration computed by CFPS. In order to plan for sufficient en route fuel capacity to handle virtually all of the aircraft, we assumed that the most reasonable value (of the CAPER/Monte Carlo duration) would be the mean duration plus two standard deviations. Our rationale is that the mean would predict enough fuel to accommodate half of the cases, whereas adding two standard deviations would accommodate $98 \%$, per normal theory. This methodology was applied consistently for both the case where there was a CNS/ATM shortfall and the case where we assumed full CNS/ATM capability. The results of these calculations for Scenario 1 are depicted in Figure 9.

The resource savings attributable to CNS/ATM capabilities are significant. For example, in examining the results for 2010, the B-52 that lacked FMI required 331,303 lbs of fuel to accomplish its mission, as compared to $270,657 \mathrm{lb}$ that would be needed if the B-52 were fully 
equipped and could fly a better route over Europe - a savings of over 18\%. This is not surprising, given that the unequipped B-52 had to fly greatly out of its way to avoid the restricted regions. The case for the fighters is less obvious, but the results are equally compelling. In the results for 2010, we see that the unequipped fighters required 990,037 lb of fuel as compared to only $787,993 \mathrm{lb}$ of fuel in the fully equipped case-a savings of over $20 \%$. In all, our analysis shows a reduction in fuel needed of 262,690 lb based on full CNS/ATM capabilities. To put this number in perspective, a KC-135E operating under ideal conditions (runway, weather, etc.) with a 1500 $\mathrm{nm}$ mission radius can offload 55,800 lbs of fuel. The fuel savings attributable to improved CNS/ATM capabilities correspond to approximately 4.7 tanker loads of fuel. This implies a significant savings in terms of required tanker missions when the bases are located in the UK (note: this is a single mission, and not scaled to the 446 missions).

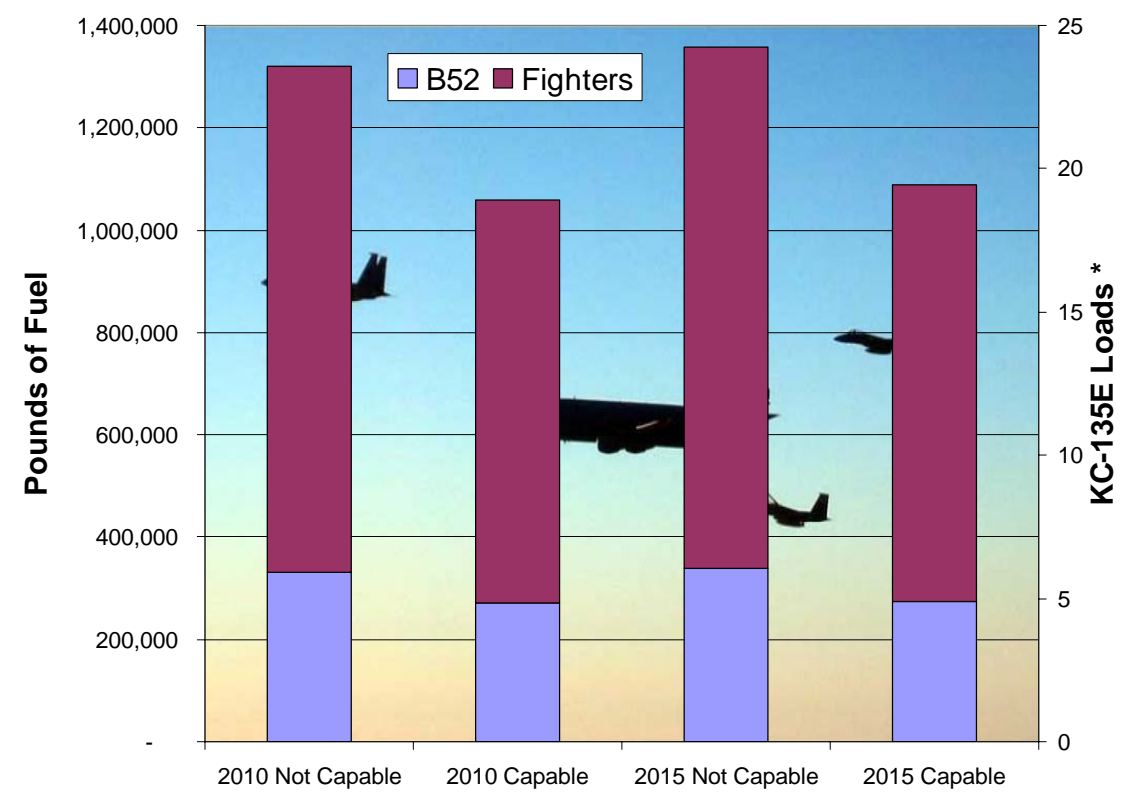

Figure 9: Round Trip Fuel Requirements

\section{Summary and Next Steps}

The second phase of the CNS/ATM Impact Analysis provides a basis for understanding operational impacts through enterprise level analysis that includes CAF-MAF interactions, military-civilian interaction, and ripple effects impacting the AOC. The hypotheses that CNS/ATM equipment improved mission operations through improved efficiencies were validated. The CNS capabilities analyzed provided significant operational improvement for the scenarios studied. Results included reduced ETA variability and associated waiting times, reduced tanker utilization and fuel expense, improved sortie rates, and improved capability for dynamic tasking at the AOC.

The impacts attributed to CNS equipage varied with the amount of regulated civilian airspace transited. Given our eastern Mediterranean marshalling point, aircraft based in Eastern Europe showed less impact than aircraft based in the United Kingdom, which required longer routes through more congested airspace. 
These results frequently displayed enterprise trade-off aspects. While the results need to be understood in the context of the assumptions made, the ability to illustrate these trade-offs make this approach useful for enterprise-level analysis. The trade-offs often come disguised as workarounds. Workarounds were frequently mentioned in our discussions with military pilots and air traffic controllers.

Workarounds come at a cost. Current workarounds, e.g., ALTRVs, may not be available in the future, because of shifting political and economic forces. Workarounds can maintain the ability to get to a specific place at a specific time, at least over the short run, but their use may result in a locally optimized solution that is not optimal for the enterprise. An example of this is transiting civilian airspace using less efficient air routing. Fighter platforms can still get to the marshalling point on time, but at the cost of increased tanker use. If more efficient routes could be attained, tanker use could go down resulting in fewer tankers needed-freeing up scarce dollars that could be used elsewhere.

Our model-based analysis framework is maturing and now provides granularity sufficient to investigate individual platforms using specific CNS/ATM capabilities in the context of specific CONOPS through civilian airspace. The data and modeling infrastructure provides added realism, allowing reasonable assumptions and 5-10 year projections. Projections were based on standard sources, especially EUROCONTROL and the GANS IPT's CNS/ATM Roadmap. Nearly this entire infrastructure is reusable.

The model-based analysis framework can support enterprise decision processes. These include developing, expanding, and refining the CNS/ATM roadmap for new capabilities, new platforms, and new scenarios. It also provides a means for addressing specific issues, e.g., addressing funding reduction of the E8 CNS/ATM program. This framework can extend current models for the area of operations by providing added realism for what is now assumed to be unhindered aircraft availability.

Results were presented to the GANS Standing/Working IPTs in October 2005. The IPT leadership endorsed the results and recommended additional next steps. Chief among these was the impact analysis of CNS/ATM capability on training focused on Air Education and Training Command (AETC).

This model-based capability will be exercised further in the upcoming year during a third phase. Current plans are to include the assessment of additional CNS/ATM capabilities such as RNP/RNAV and ADS-B, and assessing the future impact of unattended air systems on nextgeneration air traffic systems (NGATS), given widespread use by both military and civilian sectors in addition to investigating impacts to training. 


\section{Acknowledgement}

The authors appreciate the efforts of MITRE staff that performed the software development and data collection for the CAPER runs: Ted Cochrane, Kyle Jaranson, Matt McNeely, Tim Stewart, and Mike Tran. In addition, MITRE staff Joe Comeaux and John Witucki provided invaluable help in defining the scenarios used in this study.

\section{References}

1. [CNN,1996-1] Cable News Network, "Commerce Secretary Brown, 32 Others Confirmed Dead”, http://www.cnn.com/US/9604/04/brown_dead/, April 1996.

2. [CNN,1996-2] Cable News Network, "Pilot Error, Poor Equipment Blamed for Brown Plane Crash”, http://www.cnn.com/US/9606/07/brown.crash/, June 1996.

3. [USAF, 2001] United States Air Force, "Global Air Traffic Management And Navigation Safety Certification for USAF Aircraft”, Air Force Policy Directive 63-13, March 2001.

4. [Shlapk et al., 2002] A Global Access Strategy for the U.S. Air Force, RAND, Santa Monica, CA, 2002.

5. [Wang, Wojcik, Mayer, 2005] "Communications, Navigation, and Surveillance Events Simulation for the National Airspace System”, Proceedings of the 2005 Winter Simulation Conference, Fort Lauderdale, FL, December 2005.

6. [Kuhl, Weatherly, and Dahmann, 1999] Creating Computer Simulation Systems: An Introduction to the High Level Architecture, Prentice, Jersey City, NJ, 1999.

7. [MITRE, 2006] The MITRE Corporation, Corporate web site: < http://www.mitre.org>.

8. [EUROCONTROL, 2005] EUROCONTROL, "Medium-Term Forecast Flight Movements (2005-2011)”, Volume 1, Edition 2.0, March 2005.

9. [Langley AFB, 2005] Correspondence with Aircraft Systems Division ACCA89 at Langley AFB, 2005.

10. [Wright, 2005] Conversation with Michael Wright, The MITRE Corporation, May 2005.

11. [Witucki, 2005] Conversation with John Witucki, The MITRE Corporation, June 2005.

12. [ASA, 2005] A.S.A. Srl, Corporate web sage: <http://www.asalink.net/>.

13. [Flynn, Benhouar, and Christian, 2003] Flynn, G., Benhouar,A., Christian, R., "Pessimistic Sector Capacity Estimation” EEC Note 21/03, EUROCONTROL, Brussels, Belgium, November 2003.

14. [ATO, 2001] ATO Manpower Study AFO Tactical Techniques and Procedures 3-2.2, 2001.

15. [Hubbard and Bristol, 2005] Conversations with Richard Hubbard and Bruce Bristol, The MITRE Corporation, September 2005. 
16. [Filipietz, 2005] Conversation with USAF Major Christopher Filipietz, September 2005 at The MITRE Corporation. 